\title{
MemÓria CULTURAL E MODOS DE TRANSMISSÃO NOS ROMANCES CONTEMPORÂNEOS DAS AMÉRICAS
}

CulTuRAL MEMORY AND MODES OF TRANSMISSION IN CONTEMPORARY NOVELS FROM THE AMERICAS

Ana Maria Lisboa de Mello

Universidade Federal do Rio de Janeiro Rio de Janeiro, RJ - Brasil ORCID 0000-0002-0651-1974

BERND, Zilá. A persistência da memória. Romances de anterioridade e seus modos de transmissão intergeracional. Porto Alegre: BesouroBox, 2018.

Memória e transmissão estão intimamente associadas: o processo fragmentário e sempre recomeçado da rememoração encontra seu sentido na transmissão.

Zilá Bernd

O livro $A$ persistência da memória traz relevantes resultados de pesquisa da investigadora Zilá Bernd sobre as relaçôes literárias interamericanas contemporâneas, o papel da memória, da genealogia e filiaçóes no romance das duas últimas décadas, com reflexóes teóricas sobre memória cultural. Bernd coloca em confronto diferentes abordagens teóricas de pesquisadores do mesmo campo de interesse, sobretudo francófonos, com destaque para o romance memorial (Régine Robin) e o romance de filiação (Dominique Viart; Laurent Demanze), adotando uma perspectiva comparada tanto no que se refere a reflexóes dos teóricos com os quais dialoga, quanto no que diz respeito às obras literárias selecionadas como corpus para as suas análises.

A memória cultural, tal como apontam teóricos como Aleida e Jan Assmann e Andreas Huyssen, cujas ideias vêm ao encontro das reflexóes da pesquisadora brasileira, não se refere apenas a dados 
armazenados em arquivos, mas inclui também tudo aquilo que escapa ao registro oficial, tais como o residual, o obliterado, o reprimido. De acordo com Bernd, a memória cultural incorporaria, portanto, o que foge do registro hegemônico do poder, com tentativas de construção de uma identidade nacional sólida e totalizante, e absorve os elementos da esfera do sensível e do simbólico, sendo que a sua construção depende da transmissão geracional.

O papel de transmissáo fica explícito no ensaio autobiográfico de Régine Robin, Le roman mémoriel (1989), que reúne textos críticos e narrativas de vidas de pessoas que foram obrigadas a "silenciar, a esquecer e a reprimir para sobreviver" (BERND, 2018, p. 23), como o que ocorreu com a comunidade judaica. Observa a pesquisadora que Robin insere nesse livro uma passagem do seu próprio romance La Québécoite (1983), em que a personagem rememora nostalgicamente o que ela e a família faziam, quando refugiados na França, durante a ocupação nazista no seu país, a Polônia: os livros que liam, os exercícios de piano, objetos que decoravam a casa, fotos, entre outras lembranças. Enfim, trata-se de uma memória cultural polifônica e mais vívida no texto ficcional do que na escrita da História e em dados de arquivos.

No que se refere à questão da transmissão geracional, Zilá Bernd e Rodrigues Soares (2016), em artigo intitulado Modos de transmissão intergeracional em romances da literatura brasileira atual, já haviam assinalado que o romance memorial “[...] está [...] associado à transmissão da memória cultural, à transmissão inter e transgeracional e à postura do sujeito narrador de assumir-se como herdeiro - para dar continuidade ao patrimônio memorial herdado - ou romper com ele”. (BERND; SOARES, 2016, p. 408)

Quase duas décadas depois da publicação do livro de Régine Robin, Dominique Viart centra-se no estudo dos romances denominados parentais ou de filiação, que são narrativas preocupadas com temática da ascendência, ancestralidade dentro do espectro do que se pode denominar "escritas de si". Essa expressão introduz uma distância que afasta o perigo do egocentrismo e egotismo, em substituição a "escritas do Eu" (Georges Gusdorf). As escritas de si reúnem um conjunto de categorias, tais como autobiografia, diário íntimo, correspondência, memórias e a autoficção. Para Bernd, nas narrati- 
vas contemporâneas, a interioridade de narradores-protagonistas é marcada por uma volta ao passado - anterioridade - ancorada nas rememoraçóes e reminiscências. Esse retorno aos ancestrais e às suas histórias, a partir de vestígios deixados por eles (fotos, objetos, cartas etc.), é na verdade uma necessidade de o eu-narrador “[...] promover a reconstrução de trajetórias vividas por seus ancestrais e, através desse processo, (re)significar e/ou (re)construir o presente"(BERND, 2018, p. 47).

Além da contribuição de Viart, para traçar o perfil do romance de filiação na contemporaneidade, Zilá Bernd destaca os aportes de Laurent Demanze que, em Encres orphelines (2008), retoma e discute o estudo de Viart sobre o romance de filiação, e acrescenta novas reflexôes sobre as manifestaçóes desse subgênero na ficção contemporânea. A pesquisadora aponta para o fato, assinalado por Demanze, que, por vezes, o passado do narrador de um romance de filiação é um capítulo vazio da memória que o sujeito tenta reconstruir por meio de pesquisas genealógicas e investigaçóes imaginárias; entretanto, esse passado mostra-se inalcançável, de transmissão impossível, de modo que a relaçáo do indivíduo contemporâneo com seu passado pode ser atingida pelo selo da perda.

Bernd assinala que o romance de filiação geralmente emprega os seguintes mecanismos de transmissão em relaçáo ao passado: um empenho do narrador em recuperar e preservar a memória da história familiar, atuando como um porta-voz dos antepassados; um processo narrativo que revela uma memória envergonhada ou ferida, que rejeita o passado familiar e faz ajustes de contas; uma narrativa que introduz elementos novos pelo narrador, os quais dão margem a uma negociaçáo com o passado e pode articular mais de um modo de transmissão.

Tanto o romance memorial como o de filiação se particularizam pelo caráter da "anterioridade", já que para falar de si o narrador busca a figura de um ancestral, como pais, avós ou até um ancestral mítico. Em síntese, Bernd aponta as duas variantes do romance de anterioridade:

1. Romance memorial, que seria uma faceta pós-moderna da saga, com ênfase na busca de vestígios, rastros, fragmentos olvidados 
no passado e que constituem a memória cultural, definida por Régine Robin como aquela feita 'de pequenos nadas' (BERND, 1989, p. 21);

2. Romance de filiaçấo (ou parental), variante da autoficção com a característica de usar o subterfúgio de focalizar a narrativa na vida de um ancestral (pai, mão, avós), numa perspectiva de ajuste de contas com o passado; neste caso, temos presença do que Laurent Demanze chama de 'herdeiro inquieto e problemático', que hesita entre reivindicar a herança paterna ou repudiá-la. (BERND, 2018, p. 25)

$\mathrm{Na}$ análise do corpus selecionado, relativo a obras ficcionais nas três Américas, de autores brasileiros, antilhanos francófonos e quebequenses, a pesquisadora aponta tendências comuns de escritores que pertencem a "comunidades de memória", expressão de Pierre Ouellet, no livro Testaments (2012), para dar conta de contextos que, como o do Quebec, acolhem povos de diferentes países, com suas tradiçóes e histórias. Essas passam a formar, juntos com os autóctones, uma memória múltipla e aberta a trocas. E Bernd cita depoimento de Ouellet, em entrevista de 2015 publicada na Revista Letras de Hoje, em que ele deixa nítida essa visão de partilha de diferentes memórias:

Não se trata de uma memória comum (coletiva) porque ela pertence a várias tradiçóes, com diferentes histórias, desenvolvidas em diversos lugares, mas o fato de que pessoas de diferentes origens participem agora da sociedade quebequense faz com que vivamos em comunidade de memórias. (OUELLET apud BERND, 2018)

Assim, à luz de sólida investigação teórica, Zilá Bernd, em A persistência da memória, analisa obras de autores de comunidades de memórias que, em romances de filiação, partilham tradiçóes, reminiscências, traumas, como romances dos brasileiros Moacyr Scliar, Ana Maria Gonçalves, Conceição Evaristo, Tatiana Salem Levi, Cíntia Moscovich, Adriana Lisboa e Eliane Brum. São objeto de análise também romances das quebequenses Louise Dupré, Catherine Mavrikakis e Francine Noël; e obras do escritor André Schwartz-Bart, que emigrou para Guadalupe. Além desses, nas passagens de reflexóes teóricas, a pesquisadora cita outras obras, de autores que escreveram 
romances de filiação nas Américas, com narradores que interrogam o passado de seu núcleo familiar ou de algum predecessor, como forma de ajuste de contas.

Bernd observa que essas narrativas de filiação podem mesclar focos em primeira e terceira pessoas, como forma de recuperar um passado do qual o narrador não participou e, portanto, não foi testemunha, mas que, no entanto, pode ter sido decisivo para a sua existência atual. Percebe-se, nesses romances contemporâneos, alternâncias de focos narrativos, como recurso para iluminar a história do protagonista e abrir portas que permitam desvendar segredos, preencher lacunas da sua história. Nos romances analisados, a investigadora aponta para a preservação da memória cultural, construída "a partir dos restos e vestígios memoriais" (BERND, 2018, p. 160), indiciadores do passado.

As obras literárias, analisadas por Bernd bem como as que serviram de exemplo para suas abordagens teóricas, formam um corpus de pesquisa que inclui obras de escritores de famílias de imigrantes, que buscaram refúgio no Novo Mundo, as quais apresentam narradores que rememoram o passado dos ancestrais para compreensão de si mesmos, bem como de escritores autóctones, que dialogam com o passado para estabelecer uma continuidade geracional e preservar legados familiares. Nos dois casos, podem surgir narradores em conflito com o passado familiar - caso do "herdeiro problemático" de Demanze - que, através da escrita, procuram liberar-se de uma história pautada por angústias e sofrimentos. Para Zilá Bernd,

Os romances memorial e de filiação revogam de certa forma essa tendência da modernidade de arquivar seu passado. Destacando erros e acertos, encontros e desencontros dos ascendentes, a perspectiva transgeracional das narrativas de filiação recompóe áreas de sombra do passado e se constitui como estelas, marcos ou monumentos dedicados a essa ascendência. [...] O romance de filiação, alimentando-se da memória cultural, pode dar as respostas que a perspectiva histórica não soube fornecer. (BERND, 2018, p. 156-157) 
A persistência da memória é um título inspirado na tela do surrealista Salvador Dalí, de 1931, com "relógios derretidos", que já não marcam a passagem temporal porque não estão em pleno funcionamento. Segundo Bernd, com a imagem dos relógios deformados, talvez "[...] o artista quisesse expressar que a noçáo de memória remete sempre à de esquecimento, sendo memória e esquecimento as duas faces da mesma moeda" (BERND, 2018, p. 16).

Trata-se de um livro que articula as mais recentes discussóes teóricas sobre o romance contemporâneo de anterioridade - romances memorial e de filiaçấo - e sobre a memória cultural, trazendo autores ainda não traduzidos para a língua portuguesa, e transmitindo informaçóes imprescindíveis aos pesquisadores, incluindo estudantes da área de Letras, que participam de pesquisas que têm por corpus esse gênero ficcional.

\section{Referencias bibliográficas}

BERND, Zilá; SOARES, Tanira Rodrigues. Modos de transmissão intergeracional em romances da literatura brasileira atual. Alea: Estudos Neolatinos, v. 18, n.3, 2016, p. 405-421

BERND, Zilá. A persistência da memória. Romances de anterioridade e seus modos de transmissão intergeracional. Porto Alegre: BesouroBox, 2018.

DEMANZE, Laurent. Encres orphelines: Pierre Bergounioux, Gérard Macé, Pierre Michon. Paris: José Corti, 2008.

OUELLET, Pierre. Testaments: le témoignage et le sacré. Montreal: Liber, 2012.

- Entretien avec Pierre Ouellet (Entrevista concedida a Ana Maria Lisboa de Mello, Zilá Bernd, Marie Hélène Paret Passos). Letras de Hoje, PUCRS, v. 50, n.2, abril-junho 2015, p. 229-240. Disponível em: <http://revistaseletronicas.pucrs.br/ojs/index.php/fale/article/ view/21342>

ROBIN, Régine La Québécoite - roman. Montreal: Québec/Amérique, Collection Littérature d'Amérique, 1983.

. Le roman mémoriel: de l'histoire à l'écriture du hors lieu. Montréal: Préambule, 1989. 
VIART, D. Récit de filiation. In: VIART,D.; VERCIER, B (éds). La littérature française au présent. Paris: Bordas, 2008.

Ana Maria Lisboa de Mello é graduada em Letras-Licenciatura em Português e Francês e respectivas literaturas pela Universidade Federal do Rio Grande do Sul (UFRGS), e Mestrado e Doutorado em Letras pela Pontifícia Universidade Católica do Rio Grande do Sul (PUCRS), na Área de Teoria da Literatura. Fez estágios de pós-doutoramento no Centre de Recherches sur l Imaginaire, na Université Stendhal, Grenoble III (1995-96), com bolsa do CNPq, na Sorbonne Nouvelle - Paris III (2004) e na University of Toronto (2013-2014), com bolsa CAPES. É membro associada ao Centro de Literaturas e Culturas Lusófonas e Europeias (CLEPUL) da Universidade de Lisboa, e ao Centre de Recherches sur les Pays Lusophones (CREPAL) da Université de la Sorbonne Nouvelle. Tem experiência na área de Letras, subáreas de Literatura Brasileira e Teoria da Literatura, com ênfase em poesia, narrativa, teorias e críticas do imaginário. Vinculou-se em 2017 ao Programa de Pós-Graduação em Letras Neolatinas (PPGLEN), da Universidade Federal do Rio de Janeiro, é bolsista de Produtividade em Pesquisa do CNPq e editora da revista Alea: Estudos Neolatinos. E-mail: ana.lisboa11@gmail.com

Recebido em: 13/05/2018

Aceito em: 30/07/2018 